\title{
Cerebral Cavernous Malformation
}

National Cancer Institute

\section{Source}

National Cancer Institute. Cerebral Cavernous Malformation. NCI Thesaurus. Code C84626.

A disorder characterized by malformations in the structure of the capillaries in the brain. It is caused by mutations in the CCM2, KRIT 1 and PDCD10 genes. The capillaries fill with blood and stretch, thereby creating cavernous spaces. Some patients experience headaches, seizures, or visual and hearing disturbances. Cerebral hemorrhage may also occur. 